\title{
Use of Placental Membranes for the Treatment of Chronic Diabetic Foot Ulcers
}

\author{
Jonathan N. Brantley* and Thomas D. Verla \\ Department of Surgery, Hunter Holmes McGuire VA Medical Center, Richmond, Virginia.
}

Significance: Chronic diabetic foot ulcers (DFUs) remain a challenge for physicians to treat. High mortality rates for DFU patients have pointed to the low effectiveness of standard care and lack of quality wound care products. The composition (collagen-rich tissue matrix and endogenous growth factors and cells) and functional properties (anti-inflammatory, anti-bacterial, and angiogenic) of placental membranes are uniquely suited to address the needs of chronic wounds. This led to the commercialization of placental membranes, which are now widely available to physicians as a new advanced wound treatment option.

Recent Advances: Progress in tissue processing and preservation methods has facilitated the development of placental products for wounds. Currently, a variety of commercial placental products are available to physicians for the treatment of chronic DFUs and other wounds. This review summarizes the key factors that negatively impact DFU healing (including social factors, such as smoking, vascular deficiencies, hyperglycemia, and other metabolic abnormalities), describes the structure and biology of placental membranes, and overviews commercially available placental products for wounds and data from the most recent DFU clinical trials utilizing commercial placental membranes.

Critical Issues: Although the effects of diabetes on wound healing are complex and not fully understood, some of the key factors and pathways that interfere with healing have been identified. However, a multidisciplinary approach for the assessment of patients with chronic DFUs and guidelines for selection of appropriate treatment modalities remain to be implemented.

Future Directions: The biological properties of placental membranes show benefits for the treatment of chronic DFUs, but scientific and clinical data for commercially available placental products are limited. Therefore, we need (1) more randomized, controlled clinical trials for commercial placental products; (2) studies that help to understand the timing of placental products' application and criteria for patient selection; and (3) studies comparing the functional properties of different commercially available placental products.

\section{SCOPE AND SIGNIFICANCE}

THE SCOPE OF this review is:

(1) To clarify the factors and pathways negatively affecting wound healing in diabetic patients and to share with readers a success- fully implemented patient assessment algorithm that identifies and corrects such factors in each patient.

(2) To describe the structure and relevant wound healing proper-

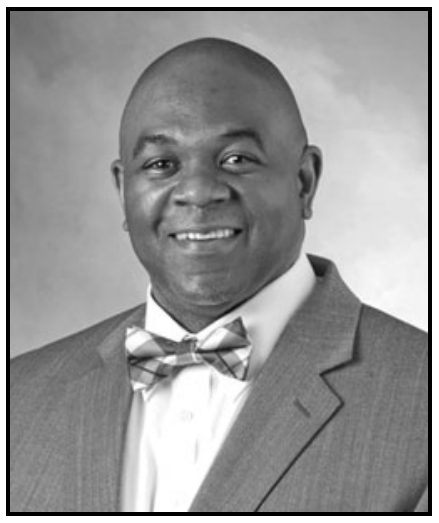

Jonathan N. Brantley, DPM

Submitted for publication January 23, 2015. Accepted in revised form March 23, 2015.

*Correspondence: Hunter Holmes McGuire VA Medical Center, 1201 Broad Rock Boulevard, Richmond, VA 23249

(e-mail: jbrantleydpm@mac.com). 
ties of placental membranes, including amnion (AM) and chorion (CM), highlighting key similarities and differences between them.

(3) To provide a classification of current commercial placental membrane products and to review available clinical data.

\section{TRANSLATIONAL RELEVANCE}

According to the American Diabetes Association, there are currently 29.1 million Americans with type II diabetes, which represents $9.3 \%$ of the population. ${ }^{1}$ Diabetic foot ulcers (DFUs) are the most common complication of diabetes, with an annual incidence of $1-4 \%$ and a lifetime risk of $15-25 \% .^{2-4}$ The annual cost for treating DFUs is estimated to be between $\$ 9$ billion and $\$ 13$ billion, which puts an enormous financial burden on our society. ${ }^{5}$ It is clear that diabetes has negative effects on wound healing. All diabetic patients should be assessed for risk factors predictive of DFUs with the main goal of preventing DFU development and recurrence. The key risk factors of DFUs include social factors, such as smoking and obesity; direct factors, such as foot deformities; and indirect factors, such as neuropathy, peripheral arterial diseases, venous stasis diseases, and other underlying conditions. However, attempts to prevent DFUs often fail. This clearly indicates that better multidisciplinary approaches for the assessment of diabetic patients and implementation of DFU prevention programs remain to be established. DFUs are often resistant to wound therapies due to the complicated diabetic wound environment that is characterized by hyperglycemia, hypoxia, and high levels of proteases, bacterial antigens, reactive oxygen species, and inflammatory cytokines. Scientists can utilize current knowledge regarding key factors and pathways that interfere with healing for the development of novel wound products that will be able to correct an abnormal diabetic wound environment.

\section{CLINICAL RELEVANCE}

Nonhealing DFUs represent a serious medical problem. Although multiple advanced treatment modalities are available, wound closure rates for such wounds remain low. Commercial placental products that are now available have the potential to address the challenges that a chronic wound presents.

\section{DISCUSSION}

\section{Assessment of factors preventing DFUs from healing}

When addressing chronic wounds, there are multiple factors that need to be taken into consid- eration. The algorithm for assessment of high-risk DFUs is presented in Figure 1. A high-risk DFU is an ulcer characterized by neuropathy and microangiopathy. Patients with high-risk DFU have the potential to heal, but an assessment of all the components on the algorithm chart must be evaluated for selection of the right treatment modalities. A description of the key assessment parameters included in the algorithm (Fig. 1) and their influence on wound healing is provided below. For more details, three books dedicated to wound healing and factors that can compromise it are recommended. ${ }^{6-8}$

Neutrophils and monocytes. A complete blood count (CBC) test with a differential panel is critical for evaluating the patient's neutrophil and monocyte levels. When a chronic wound is in the inflammatory phase, often both the neutrophil and the monocyte counts are elevated. Neutrophils are the first responders not only to the infection but also to the presence of necrotic tissue that must be removed from the wound. Monocytes/macrophages respond to the same inflammatory stimuli. They are involved in clearance of apoptotic neutrophils and denatured collagen, and they serve as a source of growth factors and pro- and anti-inflammatory cytokines. In general, elevations in the differential panel are observed in response to cellulitis, the presence of biofilm and denatured extracellular matrix (ECM), and maceration around the periphery of the wound. An appropriate strategy to combat the aforementioned clinical pathologies should be utilized. Antibiotics are required to address cellulitis. Cadexomer iodine has been shown to be efficacious in the disruption of glycocalyx in biofilm. Wounds with obvious denatured ECM must be debrided at both macroscopic (sharp surgical) and microscopic (enzymatic) levels. Exogenous enzymatic debridement using biologics, such as Santyl ${ }^{\circledR}$ (collagenase) (Healthpoint, Fort Worth, TX), have been proven to be both safe and efficacious. In the event of wound periphery maceration, a topical zinc oxide paste can provide the desired drying effect.

Social factors. Social factors, such as alcohol and drug abuse, poor personal hygiene, and tobacco abuse, are among key risk factors that not only predict development and recurrence of DFUs but also predict poor wound closure. ${ }^{9}$ Patient's education is an important step in reducing or eliminating the negative effects of social factors for prevention and successful treatment of DFUs. All patients with diabetes are required to have primary care provider supervision of their medical condition and 


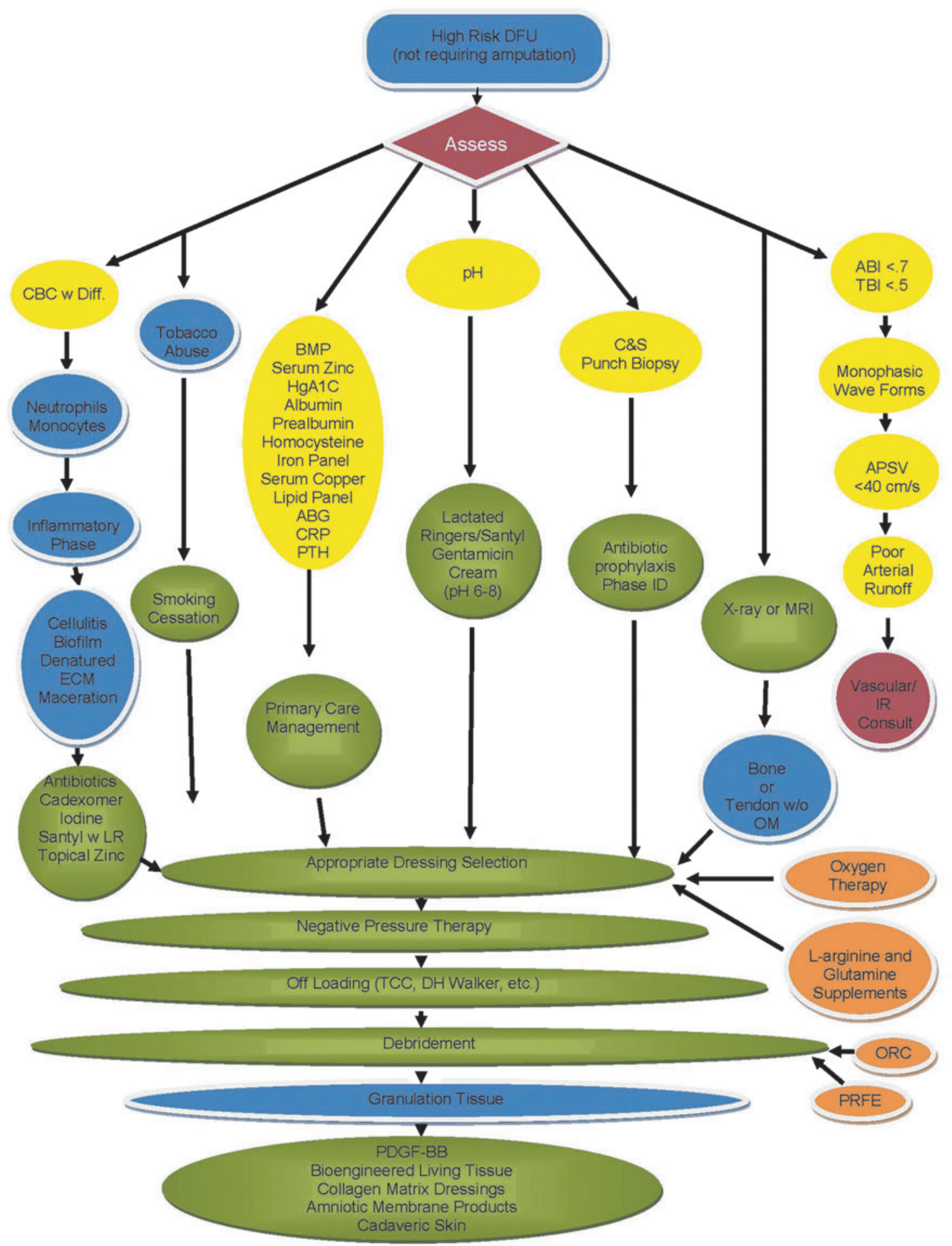

Figure 1. Treatment algorithm for the assessment of high-risk DFU patients. This algorithm was developed and implemented at the Hunter Holmes McGuire VA Medical Center. The algorithm is based on our current understanding of key factors that can impair wound healing. All patients with high-risk DFUs, which are characterized by neuropathy and microangiopathy, undergo screening before selection of wound treatment modalities. The purpose of this algorithm is for the standardization of wound treatment and the improvement of clinical outcomes. ABI, ankle-brachial index; ABG, arterial blood gases; APSV, ankle peak systolic velocity; BMP, basic metabolic panel; C\&S Punch Biopsy, culture and sensitivity punch biopsy; CBC w Diff., complete blood count with differential; CRP, C-reactive protein; DFU, diabetic foot ulcer; ECM, extracellular matrix; HgA1C, hemoglobin A1C; IR, interventional radiology; LR, lactated ringers; MRI, magnetic resonance imaging; OM, osteomyelitis; ORC, oxidized regenerated cellulose; PDGF-BB, platelet-derived growth factor-BB; Phase ID, phase identification; PRFE, pulsed radio frequency energy; PTH, parathyroid hormone; TBI, toe-brachial index; TCC, total contact cast. 
referrals to appropriate specialists in a timely manner. Among the aforementioned social factors, tobacco abuse especially has a direct negative impact on wound healing at cellular and molecular levels and should be addressed. It is known that smoking doubles the complication rate for patients undergoing surgery compared to that of nonsmokers. ${ }^{10}$ Smoking increases the level of carbon monoxide bound to hemoglobin, thereby decreasing the red blood cells' capacity to deliver oxygen. The combustion product of tobacco not only has vasoconstrictive properties but is also an irritant to the lumen of the arterial system and causes a rebound inflammatory response. ${ }^{11}$ In addition, smoking inhibits migration and proliferation of keratinocytes and fibroblasts and induces neutrophil and monocyte oxidative burst leading to prolonged inflammation. Prolonged inflammation delays collagen synthesis, and a lack of collagen deposition leads to poor tensile strength. Clinically, cigarette smoking is known to be associated with delayed healing, wound infection, and dehiscence. ${ }^{12}$ Smoking cessation must be encouraged to avoid delay of wound healing. Patients should be counseled on the evidence that even shortterm smoking cessation will improve wound healing. ${ }^{12}$ Nonsmokers with wounds should be also counseled that second-hand smoke may negatively affect healing and should be avoided. ${ }^{12}$

Biochemistry and metabolic panels. Biochemistry and metabolic panels make possible the monitoring of key factors in patients' serum to control fluctuations that impact wound healing. The panel referenced in Figure 1 provides a comprehensive list of critical factors, and the text below provides a detailed description for each factor.

Glucose and hyperglycemia. Patient's fasting and nonfasting glucose levels can be monitored by the basic metabolic panel. Hyperglycemia has a detrimental effect on wound healing. It damages the endothelium of blood vessels resulting in altered blood flow, increases vascular permeability, changes vascular growth factor expression and leukocyte/ monocyte adhesion, and eventually triggers vascular occlusion. Hyperglycemia leads to basement membrane thickening in capillaries, increased blood viscosity, cellular aging, and increased platelet aggregation with a relative decrease in the chemotactic, phagocytic, and lysosomal activity of cells. The effects are both micro- and macrovascular in nature, but microvascular disease may be more critical when considering the chronicity of wound healing. A hemoglobin A1c test provides a clinician with the knowledge of long-term glycemic control. Elevated hemoglobin A1c has a negative impact on wound healing rates. Elevated hemoglobin A1c is indicative of endothelial dysfunctions comprising nerve sensation abnormalities, capillary proliferation, precapillary fibrosis, proteinase activation, reactive oxygen metabolites, and fibrin deposition. All together, these events trigger tissue breakdown. ${ }^{13}$ Lowering hemoglobin A1c levels is important for successful wound treatment. Interestingly, recent data show that high levels of hemoglobin A1c do not affect the activity of advanced wound products containing living cells, supporting the use of such products for these patients. ${ }^{14}$

Hyperglycemia impairs wound healing by abnormal activation of four main biochemical mechanisms: (1) the polyol pathway, (2) formation of advanced glycation end products (AGEs), (3) the protein kinase $\mathrm{C}(\mathrm{PKC})$, and (4) the hexosamine pathway (Fig. 2). The main enzyme of the polyol pathway is aldose reductase, which converts excess glucose into sorbitol leading to osmotic stress on cells. Osmotic stress induces alterations in the internal cellular structures and arrangement of chromatin, as well as potential changes in the nuclear membrane influencing gene transcription and nucleocytoplasmic transport. ${ }^{15}$ During sorbitol formation, aldose reductase utilizes high amounts of nicotinamide adenine dinucleotide phosphate (NADPH), which is required to maintain reservoirs of intracellular antioxidants, such as reduced glutathione. This decreases the body's ability to combat oxidants and increases susceptibility to intracellular oxidative stress.

Hyperglycemia triggers the formation of intracellular AGE precursors, which damage the cells by several mechanisms. First, AGE precursors bind to intracellular proteins (transcription factors), lipids, and nucleic acids that negatively affect intracellular molecule functionality. Second, AGE precursors are released from cells and then bind to ECM proteins and modify their function, thereby disrupting signaling between matrix proteins and cell membrane proteins. Third, released AGE precursors modify circulating blood proteins, such as albumin. Complexes between AGEs and blood proteins will interact with AGE receptors on cells leading to pathological increases in inflammatory cytokines and growth factors released by macrophages and other cells, which in turn cause vascular pathology.

Hyperglycemia also leads to hyperactivation of PKC through an increased synthesis of diacylglycerol. PKC changes gene expression leading to a decrease in endothelial nitric oxide synthase and a simultaneous increase in endothelin-1 (ET-1), 


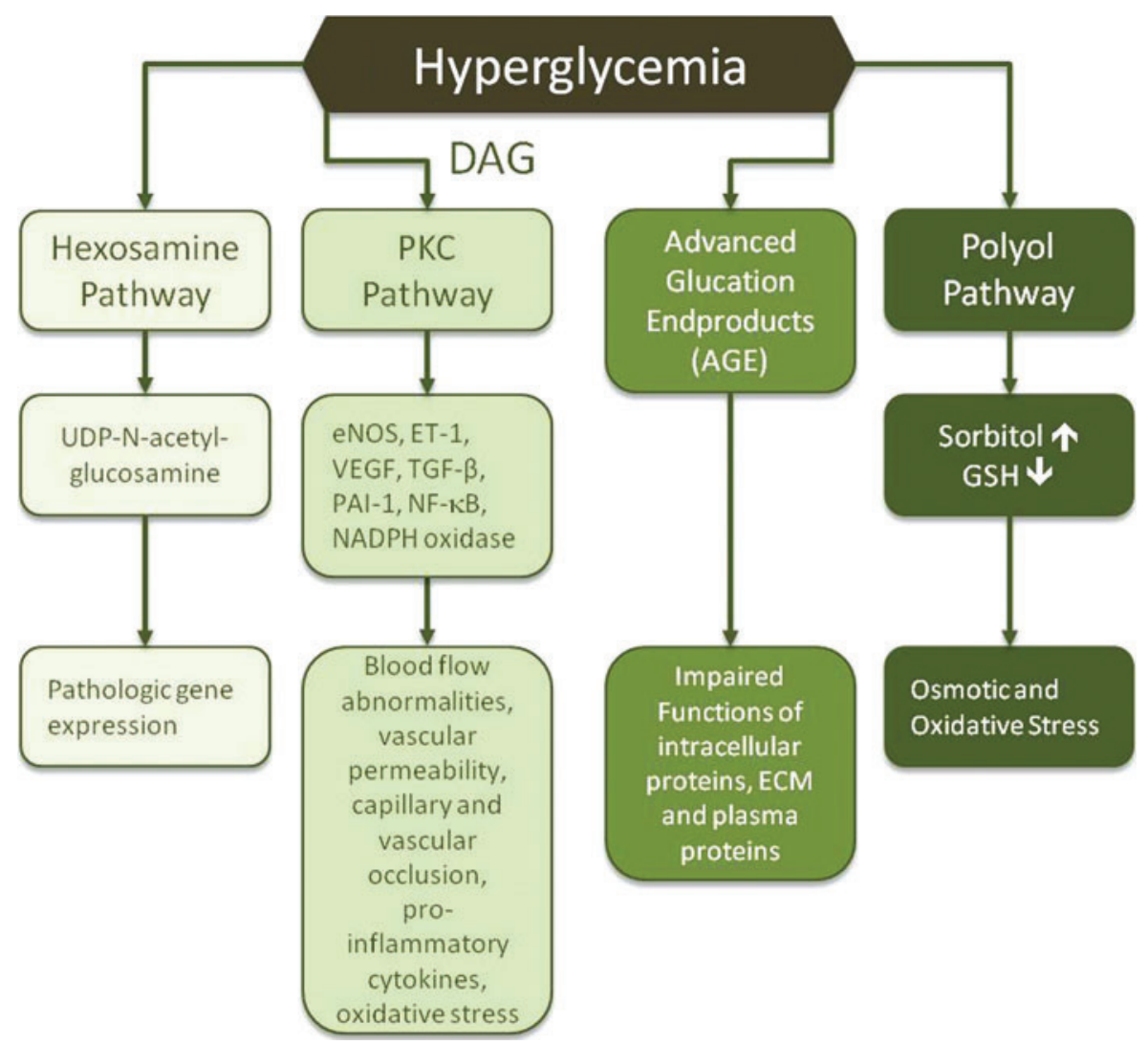

Figure 2. Effects of hyperglycemia on wound healing. Hyperglycemia impairs wound healing by four main biochemical mechanisms: (1) prolonged activation of the polyol pathway, (2) excessive formation of advanced glycation end products, (3) hyperactivation of PKC, and (4) increased activation of the hexosamine pathway. The consequences of the abnormal hyperactivation of these pathways include vascular abnormalities, changes in gene expression and functionality of proteins, and osmotic and oxidative stress, all of which have negative effects on wound healing. DAG, diacylglycerol; ECM, extracellular matrix; eNOS, endothelial nitric oxide synthase; ET-1, endothelin-1; GSH, glutathione; NADPH, nictotinamide adenine dinucleotide phosphate; NF- $\kappa$ B, nuclear factor-kappaB; PAI-1, plasminogen activating factor inhibitor-1; PKC, protein kinase C. TGF- $\beta$, transforming growth factor-beta; UDP, uridine diphosphate; VEGF, vasular endothelial growth factor. To see this illustration in color, the reader is referred to the web version of this article at www.liebertpub.com/wound

thereby causing microvascular blood flow abnormalities. It upregulates vascular endothelial growth factor (VEGF) to levels that induce vascular permeability. PKC-induced expression of transforming growth factor (TGF)- $\beta$ leads to increased collagen and fibronectin formation causing capillary occlusion by thickening the basement membrane.

A PKC-mediated increase in plasminogen activating factor inhibitor-1 (PAI-1) inhibits fibrinolysis that leads to vascular occlusion. Activation of PKC also causes an increase in nuclear factorkappa $b(\mathrm{NF}-\kappa \mathrm{b})$ that triggers the expression of proinflammatory cytokines. Additionally, there is an increase in NADPH oxidases resulting in high levels of reactive oxygen species, which have multiple effects, including cell damage and increased leukocyte adhesion to the endothelium, thus compromising functionality of the endothelial barrier.

Activation of the hexosamine pathway represents another mechanism by which hyperglyce- mia damages tissues and delays wound healing. Normally, intracellular glucose is metabolized through glycolysis, in which fructose-6-phosphate is one of the intermediates. However, excess glucose triggers conversion of fructose-6-phosphate to glucosamine-6-phosphate and finally to UDP (uridine diphosphate) $\mathrm{N}$-acetylglucosamine by the enzyme glutamine:fructose-6-phosphate amidotransferase. $\mathrm{N}$-acetylglucosamine modifies serine and threonine residues of transcription factors resulting in pathologic changes in gene expression. For example, modification of the transcription factor specificity protein 1 results in increased expression of TGF- $\beta 1$ and PAI-1, both of which lead to vascular occlusion. Biochemical pathways affected by hyperglycemia are overviewed by Brownlee. $^{16}$

Malnutrition: hydration and albumin/prealbumin. The basic metabolic panel also facilitates the evaluation of the patient's hydration status by 
monitoring the sodium level. Evidence of hypernatremia provides insight into the patient's potential to be classified as dehydrated. All cells need an aqueous environment to maintain their function, and dehydration harms cell function and impedes wound healing.

Albumin is responsible for the transportation of zinc, copper, calcium, and multiple other molecules required for wound healing. Albumin levels less than normal $(3.5-5.0 \mathrm{~g} / \mathrm{dL})$ indicate a potential state of malnutrition. However, since albumin has a relatively long half-life of 15-20 days, it is not the best indicator of immediate nutritional status. Prealbumin has been shown to be a much better predictor of malnutrition due to its shorter 2-day half-life when compared to albumin. A prealbumin level less than normal $(15-35 \mathrm{mg} / \mathrm{dL})$ is indicative of a protein-malnourished state and must be addressed. However, hydration status may affect the accuracy of albumin and prealbumin measurements. In overhydrated patients, the values of albumin and prealbumin can be low, and conversely, in dehydrated patients, an erroneous elevation may be observed. Therefore, hydration level should be taken into consideration when albumin/prealbumin levels are analyzed.

The presence of a wound indicates that the body is in a catabolic state consequently requiring an increase in protein intake. When treating a wound, $1.5 \mathrm{~g}$ of protein per kilogram of body weight is recommended in a patient's diet. With adequate nutritional support, prealbumin levels should rise $2 \mathrm{mg} / \mathrm{dL}$ (20 g/L) per day. ${ }^{17}$

Homocysteine. Homocysteine is a sulfhydrylcontaining amino acid formed during the metabolism of methionine. The normal level of this metabolite is usually $<12 \mu \mathrm{M}$. An elevated homocysteine level ( $>15 \mu \mathrm{M})$, regardless of the underlying cause, is a strong independent risk factor for occlusive vascular disease. Homocysteine has a high affinity for fibronectin and inhibits the interaction of fibronectin with fibrin. The binding of fibronectin to fibrin is important in thrombosis and wound healing. Tissue injury triggers a rapid activation of the clotting cascade and the formation of a provisional matrix, the major components of which are fibrin and fibronectin. Elevated serum levels of homocysteine decrease clotting and provisional matrix formation, along with a diminished ability of cells to adhere, spread, and migrate throughout the provisional matrix to populate the wound bed, thereby causing a subsequent delay of healing. ${ }^{18}$ Supplementation with vitamin B6, folic acid, and vitamin B12 should be used to normalize homocysteine elevation.
Iron, copper, and zinc. Iron is critically important for wound healing in multiple ways. Monitoring the patient's iron panel can give the clinician relative insight into the patient's capacity to initiate collagen synthesis and to deliver an adequate oxygen supply to the compromised tissue. Iron, ascorbic acid, and oxygen assist in posttranslational hydroxylation of proline and lysine residues in newly synthesized collagen molecules. Iron also plays a role in the activation of matrix metalloproteinases (MMPs), which is important for ECM remodeling. ${ }^{19}$

Copper is essential for the activation of lysyl oxidase, cytochrome-C oxidase, and superoxide dismutase, enzymes that are critical for biogenesis of connective tissues, mitochondrial electron chain transfer, and antioxidant defense, respectively. Copper deficiency impairs the formation of collagen fibrils by inhibition of tropocollagen cross-linking performed by lysyl oxidase. Copper deficiency also decreases iron absorption, causes demineralization of bone, neutropenia, leucopenia, and failure of erythropoiesis. $^{20}$

Zinc performs multiple functions in the body. With regard to wound healing, zinc deficiency leads to decreased epithelialization and fibroblast proliferation in the wound bed. Zinc is an irreplaceable cofactor necessary for the activation of MMPs. Zinc also appears to be essential for postreceptor binding of insulin-like growth factor-1 resulting in alterations in cell proliferation. ${ }^{21}$

Vascular assessment. Poor blood circulation is a major concern for patients with nonhealing DFUs. Several modalities are available to assess the level and/or degree of vascular disease and allow clinicians to select the most appropriate intervention to resolve vascular problems. ${ }^{22}$

Traditionally, an ankle-brachial index (ABI) and toe-brachial index (TBI) allow detection of peripheral vascular insufficiency. An ABI of greater than 0.7 with an upper limit of less than $1.3 \mathrm{and} /$ or a TBI of greater than 0.5 represent an acceptable degree of arterial inflow. However, arterial pathology present in patients with diabetic complications requires more comprehensive and reliable methods to assess vascular status distally in the lower extremity. For example, noncompressible vessels as a result of the ever-present arterial calcifications provide unreliable fluctuating values. Recently, using ankle peak systolic velocities has been suggested for vascular assessment and has been considered predictive for nonhealing DFUs. ${ }^{23}$ A cutoff value of $35 \mathrm{~cm} / \mathrm{s}$ (average of velocity measured in the anterior and posterior tibial arteries at the 
level of the ankle) was found to be sensitive and specific in predicting the healing potential of chronic DFUs. With the use of an arterial duplex ultrasound scan, an estimation of how "fast" the blood is travelling to the lower extremity, degree of perfusion, and subsequent diffusion in the low extremity can be made.

\section{Structure and biology of placental membranes}

\section{Amnion and chorion structure}

The placenta at term is discoid in shape with a diameter of $15-20 \mathrm{~cm}$ and a thickness of $2-3 \mathrm{~cm}$. Placental membranes, AM and CM, continue from the edge of the placenta and enclose the amniotic fluid and the fetus. The amniotic epithelium is a single layer of flat, cuboidal, and columnar epithelial cells in contact with the amniotic fluid. The epithelium is attached to a basement membrane, which in turn is connected to the amniotic mesoderm. The basement membrane of the amnion is one of the thickest membranes among all human tissue basement membranes. In the amniotic mesoderm closest to the epithelium, an acellular compact layer is composed of collagens type I and III and fibronectin. Below the compact layer of the AM, a network of dispersed fibroblasts and mesenchymal stem cells (MSCs) and rare macrophages are observed. A spongy layer of loosely arranged collagen fibers separates the amniotic and chorionic mesoderm. The spongy layer is loosely connected to the chorion, and the amnion can be easily separated from the chorion by blunt dissection. The chorionic membrane consists of mesodermal and trophoblastic layers. A large and incomplete pseudo basement membrane separates the chorionic mesoderm from the trophoblast layer, which is interdigitated extensively with the decidua. Mesodermal layers of amnion and chorion are similar in composition. The main function of the amnion and mesodermal layer of the chorion is to serve as a protective barrier enclosing the fetus during in utero development. The major function of the trophoblast layer is an exchange of substances between the mother and the developing fetus. Amnion and chorion contain no blood vessels or nerves; instead, the nutrients it requires are supplied directly by diffusion out of the amniotic fluid and/or from the underlining decidua. The structure of amnion and chorion is overviewed by Niknejad et al. and by Parolini et al. ${ }^{24,25}$ The microscopic structure of placental membranes is shown in Figure 3. Placental membranes are composed of ECM, growth factors, and tissue-resident cells and are described below. A comparison of amniotic and chorionic membranes composition and properties is summarized in Table $1 .^{24-43}$

\section{Extracellular matrix of amnion and chorion}

Collagens. Collagens are the major structural component of placental membranes. ${ }^{33,44,45}$ The tensile strength of placental membranes is provided by interstitial type I and III collagens together with small amounts of type V, VI, and VII collagens in the compact layer of AM, which is

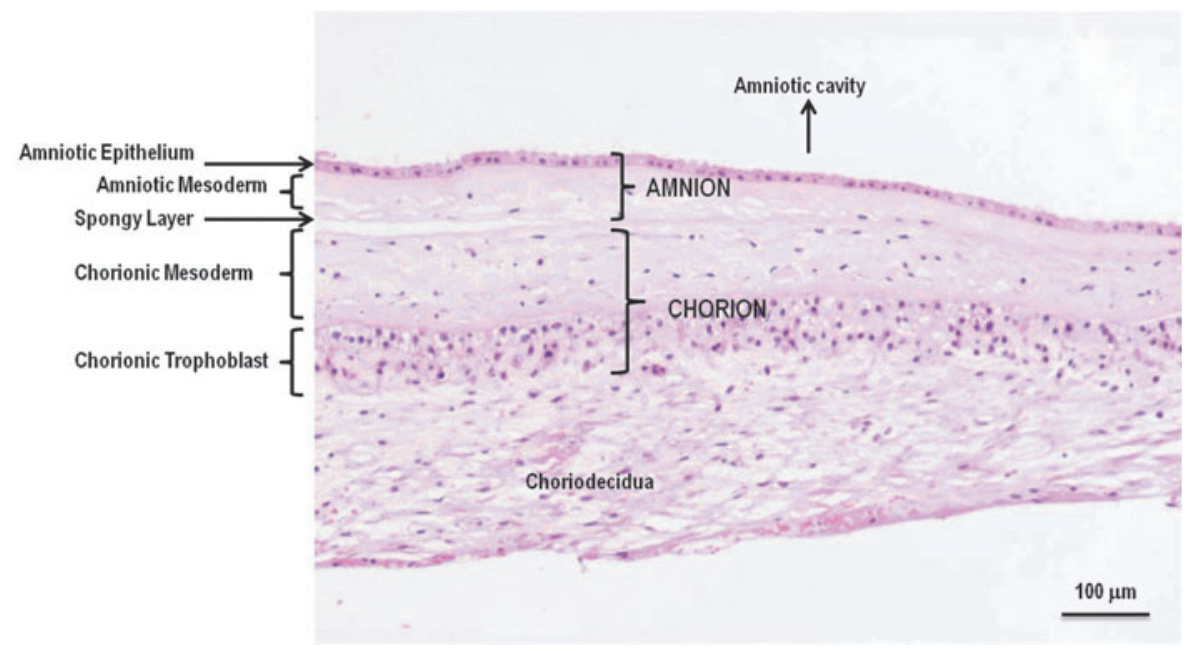

Figure 3. Human amnion and chorion microscopic structure. The amnion is composed of a single layer of epithelial cells and a mesodermal (also called stromal or fibroblastic) layer. A loose spongy ECM layer separates the amnion from the chorion. The chorion consists of a mesodermal (stromal, fibroblastic) layer and the trophoblast layer, which is tightly connected to the maternal decidua. Amniotic and chorionic mesoderm contains fibroblasts, mesenchymal stem cells, and tissue macrophages. Both amnion and chorion are avascular tissues. Here, a cross-sectional view of H\&E-stained placental membranes at term are shown (provided by Osiris Therapeutics, Inc., Columbia, MD). ECM, extracellular matrix; H\&E, hematoxylin-eosin. 
Table 1. Properties of human amnion and chorion

\begin{tabular}{|c|c|c|c|}
\hline Property & Amnion & Chorion & References \\
\hline \multicolumn{4}{|l|}{ Physical } \\
\hline Thickness & $111 \pm 78 \mu \mathrm{m}$ & $431 \pm 113 \mu \mathrm{m}$ & 26,27 \\
\hline Max tensile force & $0.166(0.15-0.25 \mathrm{~kg} / \mathrm{cm})$ & $0.117(0.05-0.1 \mathrm{~kg} / \mathrm{cm})$ & \\
\hline Max tensile stress & $30.2 \mathrm{~kg} / \mathrm{cm}^{2}$ & $5.9 \mathrm{~kg} / \mathrm{cm}^{2}$ & \\
\hline Layers & $\begin{array}{l}\text { Epithelial, basement membrane, compact, } \\
\text { mesodermal, sponge }\end{array}$ & $\begin{array}{l}\text { Mesodermal, pseudo basement membrane, } \\
\text { trophoblast }\end{array}$ & 24,25 \\
\hline Tissue-resident cells & $\begin{array}{l}\text { Epithelial cells, fibroblasts, mesenchymal } \\
\text { stem cells, macrophages }\end{array}$ & $\begin{array}{l}\text { Fibroblasts, mesenchymal stem } \\
\text { cells, macrophages, trophoblast cells }\end{array}$ & 25,28 \\
\hline Cell number (average per placenta) & $\begin{array}{l}\sim 20 \text { million stromal } \\
\text { 50-70 million epithelial }\end{array}$ & $25-40$ million stromal $^{\mathrm{a}}$ & 29,30 \\
\hline In utero function & Barrier, cover & $\begin{array}{l}\text { Stromal layer-barrier, cover; trophoblast-material } \\
\text { exchange, secretory }\end{array}$ & 25,31 \\
\hline \multicolumn{4}{|l|}{ Extracellular matrix } \\
\hline Structural matrix & Collagens I, III, IV, V, VI, elastin & Collagens I, III, IV, V, VI, tropoelastin & 24,32 \\
\hline Glycoproteins & Fibronectin, laminins, nidogen & Fibronectin, laminins, nidogen & 33 \\
\hline Proteoglycans & $\begin{array}{l}\text { Chondroitin, dermatan sulfate, hyaluronan, } \\
\text { decorin, biglycan }\end{array}$ & $\begin{array}{l}\text { Chondroitin, dermatan sulfate, hyaluronan, decorin, } \\
\text { biglycan, versican, perlican }\end{array}$ & 34 \\
\hline \multirow[t]{5}{*}{ Selected growth factors ${ }^{b}$} & $\begin{array}{l}\text { EGF, HGF, TGF- } \beta(1,3) \text {, bFGF, KGF, NGF, } \\
\text { VEGF, PDGF, PIGF, TGF- } \alpha\end{array}$ & HGF, TGF- $\beta 1$, TGF- $\alpha$, bFGF, VEGF, PDGF, PIGF & $35-37$ \\
\hline & Mucin & Interferon $\alpha$ & 38 \\
\hline & Defensins & Defensins & 39,40 \\
\hline & TIMPS, CTGF, IL-1RA & TIMP-1 & 37,41 \\
\hline & $\begin{array}{l}\text { Gro } \alpha \text {, sICAM, IL-6, IL-8, MCP-1, MIF, } \\
\text { serpin E1, SDF-1a, IL-10, IL-4, G-CSF }\end{array}$ & IL-6, IL-8, IL-4, SDF-1a, IL-10, GCSF & $37,42,43$ \\
\hline
\end{tabular}

${ }^{\mathrm{a} E s t i m a t e d ~ b a s e d ~ o n ~} 20 \mathrm{~g}$ and $25-40 \mathrm{~g}$ weight for wet amnion and chorion, respectively.

${ }^{\mathrm{b}}$ Most amniotic growth factors are also present in chorion. ${ }^{36}$

adjacent to the basement membrane. ${ }^{45}$ The basement membrane consists mostly of type IV collagen, which serves as a scaffold for the assembly of its other components: laminin, nidogen, and heparan sulfate. Collagen types V, VI, and VII in the compact layer are important for the strength of the amnion. Collagen types V and VI form heterotypic fibrils with type I and III collagens, and type VII forms anchoring fibrils. Type IV collagen is present not only in the basement membrane of the amnion but also in the pseudo basement membrane of the chorion, suggesting that type IV collagen plays a role in the development and maintenance of the placental matrix. ${ }^{45}$ Type VI and XIV collagens are distributed throughout placental membranes. ${ }^{45}$ The production of collagens is continued to term, and tissueresident placental cells are important for the maintenance of strength and for the repair of the amniochorionic tissue. ${ }^{33}$

Elastin and microfibrils. The placental membranes have viscoelastic properties attributed to the presence of elastin and microfibrils. Elastin is the amorphous component of elastic fibers, which is assembled from precursor proteins named tropoelastins. The soluble isoforms of tropoelastins are assembled outside the cells into the insoluble elastic fiber. The cross-linking of elastin results in the formation of a fiber, which can be associated with fibrillin-based microfibrils. The microfibrils are abundant in the mesenchymal layers of AM and CM as well as in the compact layer of the amnion. ${ }^{33}$

Fibronectins and laminins. Fibronectins have generalized distribution across the placental membrane matrix. They play an important role in cellmatrix interactions, which initiate cell signaling leading to synthesis of other matrix proteins. Fibronectins are a glycoprotein family derived from a single gene, which by alternative splicing can form 20 different fibronectin isoforms. Fibronectins have multiple binding domains for cells and various matrix proteins, which stabilize the whole system of cells and matrix. Most cells can adhere to fibronectin through its RGD motif (Arg-Gly-Asp). Fibronectins bind matrix proteins through collagen- and heparinbinding domains.

Laminins were first identified as products of the human amniotic epithelial cells. Laminins are present in the basement membrane, in which several subunits are linked together through disulfide bonds. Laminins are encoded by several different genes and mediate cell-matrix interactions. In amnion, laminins anchor the epithelial cells to the basement membrane and the basement membrane to the underlying stroma. Together with collagens, laminins contribute to the strength of the amnion. ${ }^{33}$ 
Proteoglycans and hyaluronan. Proteoglycans are composed of a protein core with one or more attached, sulfated, glycosaminoglycan side chains. The placental membranes contain predominantly smaller proteoglycans, such as decorin and biglycan. Decorin is involved in lateral organization of collagen type I and III fibrils, which are important for placental membrane tensile strength. Decorin is present in skin. In decorin-deficient mice, the tensile strength of skin is decreased. This supports the role of decorin as a contributor to the mechanical properties of tissues. Biglycan, another small proteoglycan, interacts with type VI collagen in the pericellular matrix. In addition to structural roles, proteoglycans are important for cell proliferation and differentiation and perform, through the binding of growth factors, essential functions in remodeling processes. For example, decorin and biglycan bind and inhibit TGF- $\beta$ activity.

Large amounts of hyaluronan (HA) are found in placental membranes, especially in the amnion. In addition, $\mathrm{HA}$ is a major carbohydrate component of the ECM that is present in skin, joints, and Wharton's jelly in the umbilical cord. HA provides mechanical support and interacts with different growth factors. ${ }^{34}$ High-molecular-weight HA contributes to the anti-inflammatory and anti-scarring properties of placental membranes, and recently, it has been reported that HA also serves as a free radical scavenger. ${ }^{46,47}$

\section{Placental membrane growth factors}

Accumulated data indicate that in addition to ECM, placental growth factors play an important role in supporting wound healing. Different growth factors are identified in the amnion and chorion. This list includes, but is not limited to, epidermal growth factor, basic fibroblast growth factor, platelet-derived growth factor, VEGF, hepatocyte growth factor (HGF), TGF- $\beta$, and keratinocyte growth factor. ${ }^{35}$ These multifunctional growth factors support migration, proliferation, and differentiation of fibroblasts, endothelial cells, and epithelial cells, which are involved in granulation tissue formation, new blood vessel formation, and reepithelialization of wounds. In addition, antiinflammatory factors (such as interleukin-10, interleukin-1 receptor antagonist, and prostaglandin E2) and antibacterial peptides (such as defensins, neutrophil gelatinase-associated lipocalin, and cathelicidin) are expressed in placental membranes. ${ }^{48-50}$ The presence of TGF- $\beta 3, \mathrm{HGF}$, and interleukin-10 contributes to the anti-scarring activity of placental membranes. ${ }^{51,52}$

\section{Tissue-resident amniotic and chorionic cells}

Amnion contains epithelial cells that are attached to the basement membrane and form the epithelial layer. The cellular composition of the mesenchymal layer of the amnion includes fibroblasts, MSCs, and a small amount of tissue macrophages. Neonatal fibroblasts, epithelial cells, and mesenchymal cells have low immunogenicity. Therefore, the amnion can be used across the human leukocyte antigen (HLA) barrier II without matching between donor and recipient. Tissue macrophages are a cell type that can potentially trigger an immune reaction. ${ }^{53}$ However, the number of tissue-resident macrophages is low, and there are no reports of adverse events linked to the presence of tissue macrophages in placental membranes. The chorion consists of two layers: mesenchymal and trophoblast. The structural and cellular composition of the mesenchymal layer of the chorion is similar to the mesenchymal layer of the amnion. ${ }^{25}$ Fibroblasts, MSCs, and rare macrophages are present in the mesenchymal layer of the chorion. The trophoblast layer of the chorion has a different structural matrix composition: the main cell population in it is trophoblast cells, the immunogenicity of which is not clear and remains to be addressed. ${ }^{31}$ This may explain common clinical use of the amnion and rare use of the chorion.

MSCs are present in all tissues in the body, including skin, and data indicate that MSCs are important for cutaneous wound healing. ${ }^{49} \mathrm{~A}$ decrease in MSC number and functionality with aging and diseases can explain the reduced healing potential in older patients with type II diabetes and other underlying conditions. ${ }^{54,55}$ Animal and clinical studies demonstrate the benefits of exogenous MSC use for nonhealing wounds. ${ }^{56}$ Both amnion and chorion are a rich source of young, potent MSCs. ${ }^{30}$ Although the contribution of MSCs to the wound healing activities of placental membranes remains to be investigated, accumulated data suggest that the presence of MSCs in wound care products may provide additional benefits.

\section{Commercial placental membrane products}

The use of placental membranes for wound healing has been reported for over 100 years. ${ }^{57}$ However, amnion was predominantly used for the treatment of burns, and the reported use of amnion for chronic ulcers was limited to a few case studies, especially for DFUs. ${ }^{58-60}$

With progress made in the field of tissue processing and preservation methods, more than 25 different commercial placental membrane products 
are available at the present time as a modality for chronic wound treatment.

Preservation of placental membranes allows for a prolonged storage time sufficient for full testing of donors and final products for communicable diseases and makes preserved placental membrane an "off the shelf," available on demand product. However, different processing methods may impact the composition and functionality of placental membranes to varying degrees. ${ }^{41,61}$ Most placental membrane products contain no viable cells. They are either dehydrated or cryopreserved with devitalized or decellularized tissue. Grafix Prime $^{\circledR}$ (amnion) and Core ${ }^{\circledR}$ chorionic mesenchyme (Osiris Therapeutics, Inc., Columbia, MD) are the only commercial placental membrane products in the market that preserve both the structural and cellular integrity of the amnion and the chorion and can be considered a true alternative to fresh placental membranes. A summary of the main commercially available placental membrane products is presented in Table 2 .

\section{Clinical experience with commercial placental membrane products}

Placental membranes are regulated as human cells, tissues, or cellular or tissue-based products (HCT/P) under 21 CFR part 1271, Section 361 of the Public Health Services (PHS) Act. In contrast to drugs and devices, tissue allografts do not require premarket approval, allowing for a faster regulatory pathway to the market. However, the common downside of tissue allografts including placental membrane allografts is a lack of clinical data at the time of marketing. Most commercial placental membranes do not have randomized, controlled clinical data, and existing data are limited to case studies presented in companies' marketing materials and/or website.

Diabetic foot ulcer case studies. Peer-reviewed published case studies utilizing commercially available placental tissue are limited to two commercial products: EpiFix ${ }^{\circledR}$ (MiMedx Group, Marietta, GA) and Grafix (Osiris Therapeutics, Inc.). Three case reports are currently available for EpiFix, which is a dehydrated amniochorion, also called dHACM. In total, 12 patients were treated in these studies who had chronic wounds with a wound age $>4$ weeks and of various etiology. Of 12 patients, 4 had surgical dehiscence, 3 patients had neuropathic DFUs, and 5 other patients had venous leg ulcers (VLU), scleroderma, snake bite, or traumatic or arterial insufficiency wounds. ${ }^{62-64}$

Three patients with neuropathic chronic DFUs were described in the Shah study. The initial wound sizes were $0.42,3.42$, and $1.32 \mathrm{~cm}^{2}$ with a duration of $4,7-8$, and 3 months, respectively. No advanced wound therapy use was reported before the application of EpiFix. Overall, after one application of EpiFix, two of three patients (66.7\%) reached complete closure at 4 and 5.5 weeks postapplication. The patient with the $3.42 \mathrm{~cm}^{2}$ wound reached $50 \%$ reduction of wound size 4 weeks posttreatment. However, it is not reported whether this patient reached complete closure. The durability

Table 2. Classification of current commercial placental membrane products (excluding amniotic fluid-based products)

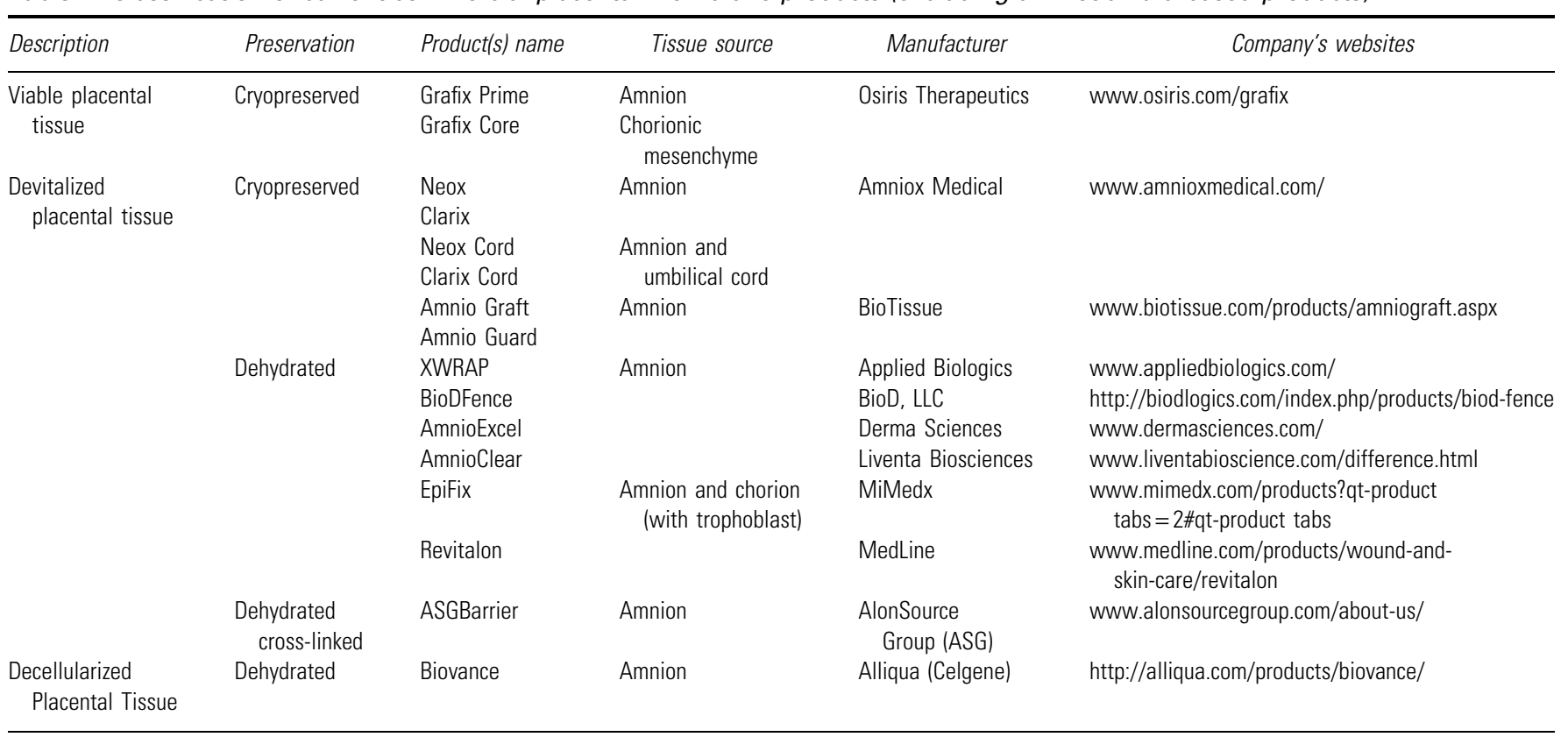


of wound closure in long-term follow-up is not provided.

The use of Grafix is reported in a retrospective single-center study. ${ }^{65}$ The analysis included 66 patients with 67 wounds, among them 27 patients with chronic DFUs, 34 patients with VLUs, and 6 patients with other types of chronic wounds (e.g., surgical, traumatic).

Twenty-three of 27 DFU patients (85.2\%) previously failed different types of advanced therapies, including collagen matrices, skin grafts, cellular skin substitutes, topical growth factors, hyperbaric oxygen therapy, and negative pressure wound therapy. The mean DFU wound size was $3.97 \mathrm{~cm}^{2}$, and the mean wound age was 24.5 weeks. By week $12,85.2 \%$ of DFU patients (23/27) reached complete wound closure.

Key patient's characteristics and outcomes for three DFU cases treated with EpiFix and for 27 DFU cases treated with Grafix are summarized in Table 3.

Prospective DFU studies. Prospective DFU trials for commercial placental membranes are limited to five studies: one open label pilot study for Biovance $^{\circledR}$ (Celgene, Warren, NJ), three randomized, controlled trials (RCTs) - two single center and one multicenter-for EpiFix, and one multicenter RCT for Grafix.

Table 3. Summary of DFU case studies for commercial placental membrane products

\begin{tabular}{|c|c|c|}
\hline & EpiFix (MiMedx) & Grafix (Osiris) \\
\hline No. of patients & 3 & $27^{a}$ \\
\hline Wound size & $\begin{array}{l}\text { Case 1: } 0.7 \times 0.6=0.42 \mathrm{~cm}^{2} \\
\text { Case 2: } 1.9 \times 1.8=3.42 \mathrm{~cm}^{2} \\
\text { Case 3: } 1.2 \times 1.1=1.32 \mathrm{~cm}^{2}\end{array}$ & $\begin{array}{r}3.97 \pm 3.08 \mathrm{~cm}^{2} \\
(\text { mean } \pm \text { SD })\end{array}$ \\
\hline Wound age (weeks) & $\begin{array}{l}\text { Case 1: } 16 \\
\text { Case 2: } 28-32 \\
\text { Case } 3: 12\end{array}$ & $24.5 \pm 49.2($ mean $\pm S D)$ \\
\hline Exclusion criteria & $\begin{array}{l}\text { End-stage renal } \\
\text { failure, previous } \\
\text { graft failure, } \\
\text { infection, } \\
\text { autoimmune } \\
\text { diseases }\end{array}$ & $\begin{array}{l}\text { Infection; ischemia and } \\
\text { malnutrition were } \\
\text { addressed before } \\
\text { application }\end{array}$ \\
\hline $\begin{array}{l}\text { Previous advanced therapy } \\
\text { failure, failed/total (\%) }\end{array}$ & $0 / 3(0)$ & 23/27 (85.2) \\
\hline $\begin{array}{l}\text { Complete wound closure, } \\
\text { closed/total (\%) }\end{array}$ & $2 / 3(66.7)$ & 23/27 (85.2), at week 12 \\
\hline Time to wound closure & $\begin{array}{l}\text { Case 1: } 4 \text { weeks } \\
\text { Case 2: Not reported } \\
\text { Case 3: } 5.5 \text { weeks }\end{array}$ & $\begin{array}{l}6.2 \pm 2.6 \text { weeks } \\
(\text { mean } \pm S D)\end{array}$ \\
\hline No. of applications & 1 & $3.8(\text { mean })^{b}$ \\
\hline References & 64 & 65 \\
\hline
\end{tabular}

\footnotetext{
${ }^{a}$ Sixty-six patients within the study with 67 wounds, including 27 DFUs, 34 VLUs, and 6 other wounds.

${ }^{\mathrm{b}}$ Mean number of applications for all 67 wounds.
}

Biovance is a decellularized, dehydrated, human amnion that can be used in the management of noninfected partial- and full-thickness wounds. Fourteen patients with chronic refractory DFUs sized from 1 to $49 \mathrm{~cm}^{2}$ were enrolled in a pilot open label study. ${ }^{66}$ Nine patients who completed the 12 week study without deviations were included in the analysis. By week 12, 55.5\% of patients (5/9) closed their wounds, $33.3 \%$ (3/9) showed wound size reduction of $>50 \%$, and $11.1 \%$ (1/9) had $<50 \%$ wound size reduction. Results showed a benefit of the amnion for the treatment of refractory chronic DFUs. However, no other studies were conducted to validate the results of this pilot study.

Results of three randomized trials using Epifix in the treatment of DFUs are available. The first one is a nonblinded, single-center RCT that enrolled 25 DFU patients (12 in the control arm and 13 in the treatment arm). After 6 weeks, 92\% of wounds treated with EpiFix reached complete wound closure versus only $8 \%$ in the control group, $p<0.001$. $^{67}$ Patients who did not respond to the standard of care (SOC) during 12 weeks in the control group of this study were offered treatment with EpiFix. Eleven patients with a mean wound size of $4.7 \mathrm{~cm}^{2}$ and 21.1 weeks of chronicity were treated biweekly with EpiFix in the crossover phase. By week 12, 91\% of wounds were reepithelialized. ${ }^{68}$ Eighteen of 22 patients from the randomized and crossover phases of the trial were followed up for 9-12 months, and $94.4 \%$ (17/18) of wounds remained closed. ${ }^{69}$

The second study, a single-center, open label, randomized trial compared weekly versus biweekly EpiFix application. Twenty patients with DFUs were treated in each arm. Overall, by week $12,92.5 \%$ of wounds reached complete closure with a mean healing time of 4.1 versus 2.4 weeks for the biweekly and weekly group, respectively. ${ }^{70}$

The third EpiFix study was conducted at three centers located in Virginia. It was an RCT comparing closure rates between three groups: control (SOC), EpiFix, and Apligraf ${ }^{\circledR} .{ }^{70}$ Twenty DFU patients per group were enrolled. By week 6, 95\% of patients in the EpiFix group achieved complete wound closure versus $45 \%$ in the Apligraf and 35\% in the control groups. No follow-up data are available at the present time. ${ }^{71}$

However, the results of these studies cannot be generalized as the number of patients in each study was small, and two of three studies were conducted at one center. One EpiFix DFU multicenter study was performed at three centers that are located in the same geographic area (Table 4). Also, the treatment of patients in the control group and the EpiFix group differs. In the control arm, patients 
Table 4. Summary of DFU prospective clinical studies with commercial placental products

\begin{tabular}{|c|c|c|c|c|c|}
\hline & Biovance (Celgene) & \multicolumn{3}{|c|}{ EpiFix (MiMedx) } & Grafix (Osiris) \\
\hline Product description & $\begin{array}{l}\text { Decellularized, } \\
\text { dehydrated } \\
\text { cross-linked } \\
\text { amnion }\end{array}$ & \multicolumn{3}{|c|}{ Dehydrated devitalized amnion and chorion (containing trophoblast) } & $\begin{array}{l}\text { Cryopreserved viable } \\
\text { amnion }\end{array}$ \\
\hline Study type & Open label & $\begin{array}{l}\text { Randomized, controlled, } \\
\text { nonblinded, single center }\end{array}$ & $\begin{array}{l}\text { Randomized, controlled, } \\
\text { nonblinded, } \\
\text { single center }\end{array}$ & $\begin{array}{l}\text { Randomized, controlled, } \\
\text { nonblinded, multicenter }\end{array}$ & $\begin{array}{l}\text { Randomized, controlled, } \\
\text { single blinded, } \\
\text { multicenter }\end{array}$ \\
\hline No. of patients & 14 (9 evaluated) & 13 treatment/12 SOC ${ }^{a}$ & $\begin{array}{l}40 \text { (20 per arm) } \\
\text { weekly/biweekly }\end{array}$ & 20 treatment $/ 20 S O C^{b}$ & 50 treatment/47 SOC \\
\hline $\begin{array}{l}\text { No. of centers } \\
\text { (geographic locations) }\end{array}$ & Not reported & 1 (VA) & 1 (VA) & $3(\mathrm{VA})$ & $\begin{array}{c}20 \text { (TX, NJ, RI, GA, OH, } \\
\text { MO, FL, CA, AZ, NY, } \\
\text { PA, AL, LA, NC) }\end{array}$ \\
\hline Wound size $\left(\right.$ mean, $\left.\mathrm{cm}^{2}\right)$ & Not reported & 2.6 treatment/3.4 SOC & 2.0 treatment/2.4 SOC & 2.7 treatment/3.3 SOC & 3.41 treatment/3.93 SOC \\
\hline Closure rate & $55.5 \%$ (week 12) & $\begin{array}{l}92 \% \text { treatment } / 8 \% \text { SOC } \\
\quad \text { (week 6) }\end{array}$ & $\begin{array}{l}95 \% \text { treatment } / 70 \% \text { SOC } \\
\text { (week 6) }\end{array}$ & $\begin{array}{l}95 \% \text { treatment } / 30 \% \text { SOC } \\
\text { (week 6) }\end{array}$ & $\begin{array}{l}62 \% \text { treatment/21\% SOC } \\
\text { (week 12) }\end{array}$ \\
\hline Mean number of treatments & 2.3 & Not reported & 2.3 treatment/2.4 SOC & $\begin{array}{l}2.15 \text { treatment/ } \\
\text { not specified SOC }\end{array}$ & 6 treatment/12 SOC \\
\hline References & 66 & $\begin{array}{l}67 \\
68 \text { (results of crossover } \\
\text { phase reported) } \\
69 \text { (follow-up results } \\
\quad \text { are reported) }\end{array}$ & 70 & 71 & $\begin{array}{l}72 \text { (results of crossover } \\
\text { and follow-up are } \\
\text { included in this } \\
\text { publication) }\end{array}$ \\
\hline Standard of care & Not specified & $\begin{array}{l}\text { Debridement, moist dressing, } \\
\text { compression dressing, } \\
\text { daily wound dressing } \\
\text { changes performed by } \\
\text { patient at home, } \\
\text { off-loading }\end{array}$ & $\begin{array}{l}\text { Weekly debridement, } \\
\text { adaptic (nonadherent } \\
\text { dressing) followed } \\
\text { by a moisture-retentive } \\
\text { dressing Nugel and a } \\
\text { compressive padded } \\
\text { dressing Dynaflex, } \\
\text { weekly wound dressing }^{\text {change, off-loading }}{ }^{\mathrm{d}}\end{array}$ & $\begin{array}{l}\text { Weekly debridement if } \\
\text { necessary, moist dressing, } \\
\text { compression dressing, } \\
\text { daily wound dressing } \\
\text { changes performed by } \\
\text { patient at home (collagen } \\
\text { alginate and gauze), } \\
\text { off-loading }\end{array}$ & $\begin{array}{l}\text { Weekly debridement, } \\
\text { adaptic (nonadherent } \\
\text { dressing) with saline } \\
\text { moist gauze or Allevyn, } \\
\text { off-loading }\end{array}$ \\
\hline
\end{tabular}

${ }^{\text {a}}$ Eleven SOC patients were enrolled in the open-label crossover phase and showed $91.2 \%$ complete closure at week 12 .

${ }^{\mathrm{b}}$ This study also had a group $(n=20)$ treated with Apligraf.

${ }^{\text {c} T w e n t y-s i x ~ S O C ~ p a t i e n t s ~ w e r e ~ e n r o l l e d ~ i n ~ t h e ~ o p e n-l a b e l ~ c r o s s o v e r ~ p h a s e ~ a n d ~ s h o w e d ~} 67.8 \%$ probability of wound closure with a mean time to closure of 42 days.

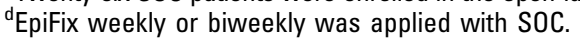

SOC, standard of care.

had to perform daily dressing changes at home, whereas in the treatment arm, dressings were changed weekly/biweekly at the doctor's office by medical personnel. Such differences in control and treatment arms may create bias. To generalize EpiFix findings, another multicenter study with a larger number of patients is required.

Results of a multicenter, blinded RCT are available for Grafix, which shows significantly higher and faster wound closure rates, with fewer wound-related infections, versus SOC. ${ }^{72}$ A total of 97 patients from 20 centers across the nation were in the trial: 50 patients with DFUs were treated with weekly applications of Grafix and 47 DFU patients received standard care. Both groups consisted of wound debridement, nonadherent dressings, and standard off-loading. In the blinded phase, $62 \%$ of Grafix patients closed their wounds versus $21 \%$ in the standard care group by week 12 $(p=0.0001)$. After 12-week follow-up, $82.1 \%$ of wounds remained closed for the Grafix group versus $70 \%$ for the standard care group.
In an open-label crossover phase of the trial, 26 patients who received standard care and in whom the wound did not close within 12 weeks were treated with Grafix weekly for up to an additional 12 weeks. After treatment with Grafix, the probability of wound closure was $67.8 \%$, with a mean time to closure of 42 days. The results of the Grafix trial provide a good basis for generalization as a large number of subjects were recruited from a wide population, and Grafix was administered in a broad range of clinical settings.

Prospective DFU study designs, key patient parameters, and outcomes for commercial placental products are summarized in Table 4.

\section{SUMMARY}

Diabetes negatively impacts DFU healing and interferes with the effects of advanced therapies that are often required for the treatment of chronic DFUs refractory to SOC. Hyperglycemia and vascular status together with wound infection, social 
factors, and malnutrition have to be evaluated in each patient and addressed before initiation of wound treatment. A standardized algorithm for DFU assessment and therapy selection is recommended for implementation at each institution, which should be a multidisciplinary effort of primary care, infectious diseases, endocrinology, and vascular and wound care specialists.

Chronic DFUs are often stalled in the inflammatory phase and are characterized by an excess of proinflammatory cytokines, oxygen free radicals, and proteases preventing wounds from healing. Accumulated data indicate that placental membranes, including the amnion and chorion, have a composition and properties that are beneficial for chronic wound treatment. The anti-inflammatory activity of placental membranes, in particular, is critical for downregulation of inflammation and for assistance of wound transition from the inflammatory to the regenerative phase of wound healing. Advances in tissue preservation methods have resulted in the development of commercial placental membrane products, which represent a promising new wound treatment modality available to physicians. More than 25 commercial placental membrane products are on the market, and the number is growing rapidly. However, with a few exceptions, the majority of placental products have neither scientific nor clinical data to support their use. A data-driven approach should be used when selecting products for wound treatment. Future development of placental products should include more scientific studies clarifying mechanisms of action, more controlled randomized clinical studies demonstrating safety and efficacy, and side-by-side scientific and clinical comparisons between commercially available placental products.

\section{ACKNOWLEDGMENT AND FUNDING SOURCE}

This work was not funded by any organizations and represents authors' personal analysis of literature data.

\section{AUTHOR DISCLOSURE AND GHOSTWRITING}

The opinions expressed are those of the authors and do not represent those of the Hunter Holmes McGuire VA Medical Center. No competing financial interests exist. This article was not written by any writer other than the authors.

\section{ABOUT THE AUTHORS}

Dr. Brantley is the Chief of Podiatric Medicine and Surgery and the Director of Podiatric Medicine and Surgery Residency Program at the Hunter Holmes McGuire VA Medical Center in Richmond, VA. Dr. Verla is a postgraduate year 3 resident at the Hunter Holmes McGuire VA Medical Center.

\section{REFERENCES}

1. Centers for Disease Control and Prevention. National Diabetes Statistics Report: Estimates of Diabetes and Its Burden in the United States, 2014. Atlanta, GA: U.S. Department of Health and Human Services, 2014.

2. Frykberg RG, Zgonis T, Armstrong DG, et al. Diabetic foot disorders. A clinical practice guideline (2006 revision). J Foot Ankle Surg 2006;45:S1-S66.
3. Boulton AJ, Vileikyte L, Ragnarson-Tennvall G, Apelqvist J. The global burden of diabetic foot disease. Lancet 2005;366:1719-1724.

4. Singh N, Armstrong DG, Lipsky BA. Preventing foot ulcers in patients with diabetes. JAMA 2005:293:217-228.

5. Rice JB, Desai U, Cummings AK, Birnbaum HG, Skornicki M, Parsons NB. Burden of diabetic foot ulcers for medicare and private insurers. Diabetes Care 2014;37:651-658.

6. Rovee DT, Maibach HL. The Epidermis in Wound Healing, 1st ed. Boca Raton, FL: CRC Press LLC, 2003

7. Falanga V. Cutaneous Wound Healing, 1st ed. London: Martin Dunitz, 2001. 
8. Sheffield PJ, Fife CE. Wound Care Practice, 2nd ed. Flagstaff, AZ: Best Publishing Company, 2007.

9. Nhan L, Strauss M, Miller S. Risk factors for diabetic foot ulcers: the first step in prevention. Consultant 2013;53:800-803.

10. Castillo RC, Bosse MJ, MacKenzie EJ, Patterson BM, Group LS. Impact of smoking on fracture healing and risk of complications in limb-threatening open tibia fractures. J Orthop Trauma 2005 19:151-157.

11. Rayner R. Effects of cigarette smoking on cutaneous wound healing. Aust $\mathrm{J}$ Wound Manage 2006;14:100-102, 104.

12. Kean J. The effects of smoking on the wound healing process. J Wound Care 2010;19:5-8.

13. Christman AL, Selvin E, Margolis DJ, Lazarus GS, Garza LA. Hemoglobin A1c predicts healing rate in diabetic wounds. J Invest Dermatol 2011;131: 2121-2127.

14. Allam RC, Van Driessche F, Zhu Y. Factors influencing efficacy of bilayered cell therapy. Adv Wound Care 2014;3:414-418.

15. Finan JD, Guilak F. The effects of osmotic stress on the structure and function of the cell nucleus. $J$ Cell Biochem 2010;109:460-467.

16. Brownlee M. The pathobiology of diabetic complications: a unifying mechanism. Diabetes 2005; 54:1615-1625.

17. Beck FK, Rosenthal TC. Prealbumin: a marker for nutritional evaluation. Am Fam Physician 2002;65: 1575-1578.

18. Majors AK, Sengupta S, Willard B, Kinter MT, Pyeritz RE, Jacobsen DW. Homocysteine binds to human plasma fibronectin and inhibits its interaction with fibrin. Arterioscler Thromb Vasc Biol 2002;22:1354-1359.

19. Wright JA, Richards T, Srai SK. The role of iron in the skin and cutaneous wound healing. Front Pharmacol 2014;5:156.

20. Borkow G, Gabbay J, Dardik R, et al. Molecular mechanisms of enhanced wound healing by copper oxide-impregnated dressings. Wound Repair Regen 2010;18:266-275.

21. MacDonald RS. The role of zinc in growth and cell proliferation. J Nutr 2000;130:1500S-1508S.

22. Donnelly R, Hinwood D, London NJ. ABC of arterial and venous disease. Non-invasive methods of arterial and venous assessment. BMJ 2000; 320:698-701.

23. Bishara RA, Taha W, Akladious I, Allam MA. Ankle peak systolic velocity: new parameter to predict nonhealing in diabetic foot lesions. Vascular 2009;17:264-268.

24. Niknejad $H$, Peirovi $H$, Jorjani $M$, Ahmadiani $A$, Ghanavi J, Seifalian AM. Properties of the amniotic membrane for potential use in tissue engineering. Eur Cells Mater 2008;15:88-99.

25. Parolini O, Alviano F, Bagnara GP, et al. Concise review: isolation and characterization of cells from human term placenta: outcome of the first international Workshop on Placenta Derived Stem Cells. Stem cells 2008:26:300-311.

26. Jabareen M, Mallik AS, Bilic G, Zisch AH, Mazza E. Relation between mechanical properties and microstructure of human fetal membranes: an attempt towards a quantitative analysis. Eur $\mathrm{J}$ Obstet Gynecol Reprod Biol 2009;144 Suppl 1:S134-S141.

27. Polishuk WZ, Kohane S, Peranio A. The physical properties of fetal membranes. Obstet Gynecol 1962;20:204-210.

28. Huppertz B. The anatomy of the normal placenta. J Clin Pathol 2008;61:1296-1302.

29. Bieback K, Brinkmann I. Mesenchymal stromal cells from human perinatal tissues: from biology to cell therapy. World J Stem Cells 2010;2:81-92.

30. Ilancheran S, Moodley Y, Manuelpillai U. Human fetal membranes: a source of stem cells for tissue regeneration and repair? Placenta 2009;30:2-10.

31. Carr MC. Biology of human trophoblast. Calif Med 1967;107:338-343.

32. Hieber AD, Corcino D, Motosue J, et al. Detection of elastin in the human fetal membranes: proposed molecular basis for elasticity. Placenta 1997;18:301-312

33. Bryant-Greenwood GD. The extracellular matrix of the human fetal membranes: structure and function. Placenta 1998;19:1-11.

34. Meinert M, Eriksen GV, Petersen AC, et al. Proteoglycans and hyaluronan in human fetal membranes. Am J Obstet Gynecol 2001;184:679-685

35. Koizumi NJ, Inatomi TJ, Sotozono CJ, Fullwood NJ, Quantock AJ, Kinoshita S. Growth factor mRNA and protein in preserved human amniotic membrane. Curr Eye Res 2000;20:173-177.

36. Lopez-Valladares MJ, Teresa Rodriguez-Ares M, Tourino R, Gude F, Teresa Silva M, Couceiro J. Donor age and gestational age influence on growth factor levels in human amniotic membrane. Acta Ophthalmol 2010;88:e211-S216.

37. Koob TJ, Lim JJ, Zabek N, Massee M. Cytokines in single layer amnion allografts compared to multilayer amnion/chorion allografts for wound healing. J Biomed Mater Res B Appl Biomater 2014 [Epub ahead of print]; DOI: 10.1002/jbmb.33265.

38. Sood R, Zehnder JL, Druzin ML, Brown PO. Gene expression patterns in human placenta. Proc Natl Acad Sci U S A 2006;103:5478-5483.

39. Buhimschi IA, Jabr M, Buhimschi CS, Petkova AP, Weiner CP, Saed GM. The novel antimicrobial peptide beta3-defensin is produced by the amnion: a possible role of the fetal membranes in innate immunity of the amniotic cavity. Am J Obstet Gynecol 2004;191:1678-1687.

40. Svinarich DM, Wolf NA, Gomez R, Gonik B, Romero R. Detection of human defensin 5 in reproductive tissues. Am J Obstet Gynecol 1997;176 470-475.

41. Thomasen $H$, Pauklin $M$, Steuhl KP, Meller D. Comparison of cryopreserved and air-dried human amniotic membrane for ophthalmologic applications. Graefes Arch Clin Exp Ophthalmol 2009;247: 1691-1700.

42. Hwang JH, Shim SS, Seok OS, et al. Comparison of cytokine expression in mesenchymal stem cells from human placenta, cord blood, and bone marrow. J Korean Med Sci 2009:24:547554

43. Paradowska E, Blach-Olszewska Z, Gejdel E. Constitutive and induced cytokine production by human placenta and amniotic membrane at term. Placenta 1997;18:441-446.

44. Burgeson RE, El Adli FA, Kaitila, II, Hollister DW. Fetal membrane collagens: identification of two new collagen alpha chains. Proc Natl Acad Sci U S A 1976;73:2579-2583.

45. Malak TM, Ockleford CD, Bell SC, Dalgleish $R$, Bright N, Macvicar J. Confocal immunofluorescence localization of collagen types I, III, IV, V and $\mathrm{VI}$ and their ultrastructural organization in term human fetal membranes. Placenta 1993;14:385406.

46. McKee CM, Penno MB, Cowman M, et al. Hyaluronan (HA) fragments induce chemokine gene expression in alveolar macrophages. The role of HA size and CD44. J Clin Invest 1996;98:24032413

47. Lockington D, Agarwal P, Young D, Caslake M Ramaesh K. Antioxidant properties of amniotic membrane: novel observations from a pilot study. Can J Ophthalmol 2014;49:426-430.

48. Rossi D, Pianta S, Magatti M, Sedlmayr P, Parolini 0 . Characterization of the conditioned medium from amniotic membrane cells: prostaglandins as key effectors of its immunomodulatory activity. PLoS One 2012:7:e46956.

49. Maxson S, Lopez EA, Yoo D, Danilkovitch-Miagkova A, Leroux MA. Concise review: role of mesenchymal stem cells in wound repair. Stem Cells Transl Med 2012;1:142-149.

50. Mamede AC, Carvalho MJ, Abrantes AM, Laranjo M, Maia CJ, Botelho MF. Amniotic membrane: from structure and functions to clinical applications. Cell Tissue Res 2012;349:447-458.

51. Ferguson MW, O'Kane S. Scar-free healing: from embryonic mechanisms to adult therapeutic intervention. Philos Trans R Soc Lond B Biol Sci 2004;359:839-850.

52. Jackson WM, Nesti LJ, Tuan RS. Mesenchymal stem cell therapy for attenuation of scar formation during wound healing. Stem Cell Res Ther 2012;3:20.

53. Banas RA, Trumpower C, Bentlejewski C, Marshall $V$, Sing G, Zeevi A. Immunogenicity and immunomodulatory effects of amnion-derived multipotent progenitor cells. Hum Immunol 2008;69: 321-328.

54. Cianfarani F, Toietta G, Di Rocco G, Cesareo E, Zambruno G, Odorisio T. Diabetes impairs adipose tissue-derived stem cell function and efficiency in promoting wound healing. Wound Repair Regen 2013;21:545-553. 
55. Rodriguez-Menocal L, Salgado M, Ford D, Van Badiavas E. Stimulation of skin and wound fibroblast migration by mesenchymal stem cells derived from normal donors and chronic wound patients. Stem Cells Transl Med 2012;1:221-229.

56. Shin L, Peterson DA. Human mesenchymal stem cell grafts enhance normal and impaired wound healing by recruiting existing endogenous tissue stem/progenitor cells. Stem Cells Transl Med 2013;2:33-42

57. Davis JW. Skin transplantation with a review of 550 cases at the Johns Hopkins Hospital. Johns Hopkins Med J 1910;15:307.

58. Kesting MR, Wolff KD, Hohlweg-Majert B, Steinstraesser $\mathrm{L}$. The role of allogenic amniotic membrane in burn treatment. J Burn Care Res 2008;29:907-916.

59. Gruss JS, Jirsch DW. Human amniotic membrane: a versatile wound dressing. Can Med Assoc J 1978;118:1237-1246.

60. Singh R, Chouhan US, Purohit S, et al. Radiation processed amniotic membranes in the treatment of non-healing ulcers of different etiologies. Cell Tissue Bank 2004;5:129-134.

61. von Versen-Hoeynck FSA, Becker J, Hermel M, Rath W, Hesselbarth U. Sterilization and preservation influence the biophysical properties of human amnion grafts. Biologicals 2008;36:248255.

62. Forbes J, Fetterolf DE. Dehydrated amniotic membrane allografts for the treatment of chronic wounds: a case series. J Wound Care 2012;21: 290, 292, 294-296.

63. Sheikh ES, Sheikh ES, Fetterolf DE. Use of dehydrated human amniotic membrane allografts to promote healing in patients with refractory non healing wounds. Int Wound J 2014;11:711-717.

64. Shah AP. Using amniotic membrane allografts in the treatment of neuropathic foot ulcers. J Am Podiatr Med Assoc 2014;104:198-202.

65. Regulski M, Jacobstein DA, Petranto RD, Migliori VJ, Nair G, Pfeiffer D. A retrospective analysis of a human cellular repair matrix for the treatment of chronic wounds. Ostomy Wound Manage 2013;59:38-43.

66. Letendre S, LaPorta G, O'Donnell E, Dempsey J, Leonard K. Pilot trial of biovance collagen-based wound covering for diabetic ulcers. Adv Skin Wound Care 2009;22:161-166.

67. Zelen CM, Serena TE, Denoziere G, Fetterolf DE. A prospective randomised comparative parallel study of amniotic membrane wound graft in the management of diabetic foot ulcers. Int Wound $\mathrm{J}$ 2013;10:502-507.

68. Zelen CM. An evaluation of dehydrated human amniotic membrane allografts in patients with DFUs. J Wound Care 2013;22:347-348, 350-341.

69. Zelen CM, Thomas, SE, Fetterolf, DE. Dehydrated human amnion/chorion membrane allografts in patients with chronic diabetic foot ulcers: a longterm follow-up study. Wound Med 2014;4:1-4.

70. Zelen CM, Serena TE, Snyder RJ. A prospective, randomised comparative study of weekly versus biweekly application of dehydrated human amnion/chorion membrane allograft in the management of diabetic foot ulcers. Int Wound $J$ 2014:11:122-128.

71. Zelen CM, Gould L, Serena TE, Carter MJ, Keller J, Li WW. A prospective, randomised, controlled, multi-centre comparative effectiveness study of healing using dehydrated human amnion/chorion membrane allograft, bioengineered skin substitute or standard of care for treatment of chronic lower extremity diabetic ulcers. Int Wound J 2014 [Epub ahead of print]; DOI: 10.1111/iwj.12395.

72. Lavery LA, Fulmer J, Shebetka KA, et al. The efficacy and safety of Grafix ((R)) for the treatment of chronic diabetic foot ulcers: results of a multicentre, controlled, randomised, blinded, clinical trial. Int Wound J 2014;11:554-560.

\section{Abbreviations and Acronyms}

$\mathrm{ABI}=$ ankle-brachial index

$\mathrm{AGE}=$ advanced glycation end product

$\mathrm{AM}=$ amnion

$\mathrm{CBC}=$ complete blood count

$\mathrm{CM}=$ chorion

$\mathrm{dHACM}=$ dehydrated amniochorion

$\mathrm{DFU}=$ diabetic foot ulcer

$\mathrm{ECM}=$ extracellular matrix

$\mathrm{ET}-1=$ endothelin-1

$\mathrm{HA}=$ hyaluronan

$\mathrm{HGF}=$ hepatocyte growth factor

$H L A=$ human leukocyte antigen

$\mathrm{MMP}=$ matrix metalloproteinase

$\mathrm{MSC}=$ mesenchymal stem cell

$\mathrm{NADPH}=$ nicotinamide adenine dinucleotide phosphate

$\mathrm{NF}-\kappa \mathrm{b}=$ nuclear factor-kappa $\mathrm{b}$

PAI- $1=$ plasminogen activating factor inhibitor-1

$\mathrm{PKC}=$ protein kinase $\mathrm{C}$

$\mathrm{RCT}=$ randomized controlled trial

$\mathrm{SOC}=$ standard of care

$\mathrm{TBI}=$ toe-brachial index

$\mathrm{TGF}=$ transforming growth factor

$\mathrm{VEGF}=$ vascular endothelial growth factor

$\mathrm{VLU}=$ venous leg ulcer 